\title{
Family Leave Provisions in New Zealand Industrial Documents
}

\author{
Michael Law*
}

This note summarises the findings of a comprehensive research programme designed to provide a detailed analysis of the family leave provisions in registered New Zealand Awards and Agreements. The project was initiated as a direct consequence of the difficulties experienced in researching material for an article on the Government's Maternity Leave and Protection of Employment Bill (Sissons and Law, 1980). This and another exercise' required access to detailed research into current award trends; regrettably such information appeared to be unavailable. A further motivation was the widespread disappointment the toothless inadequacy of the final maternity legislation ${ }^{2}$ which indicated a need to provide union advocates and members, particularly women, with detailed analyses of the progress being made in award negotiations.

\section{Introduction}

The New Zealand Federation of Labour (FOL), the New Zealand Employers' Federation, the Department of Labour and individual unions all monitor award trends, but it is not surprising that few attempts have been made to publish comprehensive analyses. New Zealand industrial documents are complex. In addition to the core considerations of wage rates, allowances and basic conditions, each will contain a combination of clauses affording particular conditions to the workers covered by that document. Not only do the combinations of clauses vary between awards, so also do the details of such clauses. Furthermore, although the award round is generally regarded as commencing from 1 August, in practice the process is continuous with some documents being negotiated as late as June/July. Thus it is difficult to freeze the process in order to report on the state of play. An additional complication is the expansion in the number of awards and agreements as unions and employers seek separate documents to cover either sub-groups of workers or house agreements for those employed by a single enterprise. Many such agreements are supplementary to the principal award and are often unregistered. This research must be qualified, in that despite the co-operation of the Registrar of the Arbitration Court and despite the assiduousness of the research assistants, it is inevitable that some documents will have been unintentionally omitted. As for the timing of the freeze, this article records the state of award provisions as at 1 February 1981.

\footnotetext{
* Continuing Education Officer, University of Waikato. The author wishes to acknowledge the assistance of: the Registrar of the Arbitration Court, the Hamilton office of the Department of Labour, Dr Colin Beardon, John Allen, Arun David, Eilish Hegarty, Alan Somerville, Keith Tibble and Carol Cramp.

It is intended that detailed reports on: (a) paid education leave; (b) family leave provisions; (c) union business will be available by late 1981 together with an appendix listing all documents analysed and the type of provisions they contain. Those interested in obtaining this material are invited to contact the author at: Centre for Continuing Education, University of Waikato, Private Bag, Hamilton.

1 A similar project analysing union business provisions on industrial documents. It is hoped that the results of that study will be available in a later issue of this journal.

2 See the article by Szakats in this issue. Ed.
} 


\section{The Scope of the Study}

Three types of leave have been examined: maternity, paternity and domestic. Bereavement leave, which could be regarded as part of this grouping, was omitted. In addition to establishing whether or not a document contains each of the provisions, the researchers ought to establish the following:

Maternity Leave

a) Qualifying service: Less than one year/one year or longer

b) Length of leave: More than six months/six months or less

c) Prospect of re-employment: Probable/possible

d) Status on re-employment: Same or better/possibly lower

e) Part of full payment for leave: Yes/no

Domestic Leave

a) For what purpose?: Sick spouse or child/spouse only or child only

b) Length of leave: More than five days/five days or less

c) Payment for leave: Yes/no

d) Status of leave: Additional/debited against sick leave entitlement

Paternity Leave

a) Length of leave: More than five days/five days or less

b) Payment for leave: Yes/no

c) Status of leave: Additional/debited against another entitlement

\section{Method and Classification}

The Court allocates each registered agreement a Document Number. This usually remains the same each year. In this survey, the year of the document was indicated by a prefix: $Z=1979, A=1980, B=1981$, etc. The type of document was recorded by adding an alphabetical suffix: $\mathrm{N}=$ National document, $\mathrm{P}=$ Principal, $\mathrm{S}=$ Supplementary. This information was then computerised. By arrangement with the Registrar of the Arbitration Court, documents have been forwarded on registration. This has allowed the researchers to maintain contemporary records. Where a 1980/81 document was for some reason not available, the preceding document was examined.

Document classification initially provided some difficulties. Those that stand on their own have been categorised as National or Principal documents. National Documents are, for convenience, the same 235 documents used by the FOL research office in its award analyses. Principal documents are all other complete awards and agreements which stand on their own. There was also a need to identify and distinguish those awards and agreements which vary some aspect of the main award or which add a new provision where the main award is silent. The category Supplementary Document has been introduced to provide for this type of document. Where the Supplementary document contains a family leave clause it has normally been included in the analysis, otherwise it has been discarded.

Table 1 Type of Document

\begin{tabular}{lrrrrr}
\hline TYPE OF DOCUMENT & 1978 & 1979 & 1980 & 1981 & Total \\
National & 2 & 52 & 155 & 26 & 235 \\
Principal & 45 & 125 & 401 & 29 & 600 \\
Supplementary Included & 4 & 6 & 23 & 3 & 36 \\
TOTAL INCLUDED & 51 & 183 & 579 & 58 & 871 \\
Supplementary Excluded & 18 & 47 & 178 & - & 243 \\
\hline
\end{tabular}


Table 1 summarises, by calendar year, the 1114 documents examined in the course of this research. In total, researchers have sought to establish 28 separate points about each document. These have been recorded on summary sheets and computerized. The relevant clauses have been xeroxed and bound in folders for more detailed scrutiny at a later date. As new documents are received, the data are updated. It is intended to run the computerized data at six monthly intervals, thus enabling trends to be regularly monitored.

\section{Principal Trends:}

\section{Maternity Leave}

Prior to the introduction of government legislation, there was evidence that unions were making advances in claims for maternity leave. Many of these award clauses were superior to the entitlements proposed in the legislation (Sissons and Law 1980). At the end of the 1979/80 award round, 120 (51.3 percent) of National Awards contained maternity leave provisions ${ }^{3}$. The $1980 / 81$ round has so far brought little further improvement, employer attitudes no doubt being affected by the eventual enactment of minimum legislation in late 1980 . Table 2 illustrates the current position.

Table 2 Maternity Leave Provisions

\begin{tabular}{lrrrrr}
\hline TYPE OF DOCUMENT & \multicolumn{2}{c}{ WITH } & \multicolumn{2}{c}{ WITHOUT } & \multicolumn{2}{c}{ Total } \\
& No. & $\%$ & No. & $\%$ & \\
National & 125 & 53.2 & 110 & 46.8 & 235 \\
Principal & 183 & 30.5 & 417 & 69.5 & 600 \\
Supplementary' & 6 & 16.7 & 30 & 83.3 & 36 \\
TOTAL & 314 & 36.0 & 557 & 64.0 & 871 \\
\hline
\end{tabular}

1. In many cases the provision will be included in the national or principal document to which the supplementary one relates.

With respect to the detail of maternity provisions, just over half the documents (59 percent) require less than 12 months service or specify no period at all. In most cases (87 percent) the leave is limited to six months; this usually commences four weeks prior to the birth of the child. In only 1 percent of documents is there a payment to cover part of the leave period. These tend to be state related documents. Turning to more subjective judgements, we rated re-employment probable in 61 percent of cases; the rest only possible. When a mother is re-employed, service entitlements are usually retained, however in only 31 percent of cases did it seem assured that re-employment would be at the same grade. Significantly, in 95 percent of those cases where the grading seemed assured, re-employment was rated as probable.

\section{Domestic Leave}

At the end of the 1980 award round, 160 (68.4 percent) of national awards contained domestic leave provisions. The situation continues to improve as Table 3 indicates. Domestic leave patterns are more uniform than for maternity leave. In 77 percent of cases the leave can be taken in the event of either a sick spouse or a sick child. Some clauses qualify this by imposing an upper age in the case of the child. Most leave entitlements are restricted to five days or less ( 78 percent); in all but one case domestic leave is paid although the common practice ( 95 percent) is to debit such leave against another entitlement, usually sick leave.

3 Information relating to national documents at the end of the $1979 / 80$ round has been supplied by the Research Office, NZ FOL. 
Table 3 Domestic Leave Provisions

\begin{tabular}{lrrrrr}
\hline TYPE OF DOCUMENT & \multicolumn{2}{c}{ WITH } & \multicolumn{2}{c}{ WITHOUT } & Total \\
& No. & $\%$ & No. & $\%$ & \\
National & 170 & 72.3 & 65 & 27.7 & 235 \\
Principal $_{\text {Supplementary }}^{1}$ & 363 & 60.5 & 237 & 39.5 & 600 \\
TOTAL $^{-16}$ & 44.4 & 20 & 55.6 & 36 \\
& 549 & 63.0 & 322 & 37.0 & 871 \\
\hline
\end{tabular}

1. See note under Table 2.

\section{Paternity Leave}

Outside the state sector, the awarding of paternity leave appears to be developing at a very slow pace. Table 4 depicts the current situation. Where this leave exists, the length is generally in excess of five days with only 17 percent of documents restricting the leave to five days or less. Just over half the awards ( 53 percent) permit paid leave, but in only three cases is that an additional paid leave. All three are clerical documents covering a very small number of eligible employees. In all other cases the paid paternity leave is debited against some other form of leave. Where unpaid leave is granted, it is, of course, additional.

Table 4 Paternity Leave Provisions

\begin{tabular}{lrrrrr}
\hline TYPE OF DOCUMENT & \multicolumn{2}{c}{ WITH } & \multicolumn{2}{c}{ WITHOUT } & Total \\
& No. & $\%$ & No. & $\%$ & \\
National & 17 & 7.2 & 218 & 92.8 & 235 \\
Principal & 52 & 8.7 & 548 & 91.3 & 600 \\
Supplementary' & 1 & 2.8 & 35 & 97.2 & 36 \\
TOTAL & 70 & 8.0 & 92.0 & 871 & \\
\hline
\end{tabular}

1. See note under Table 2.

\section{Summary}

It has not been possible yet to correlate completely all instances of family leave, however the principal patterns may be depicted as

Combination

Maternity only

Domestic only

Paternity only

Maternity and domestic only

Maternity and Paternity only

Domestic and Paternity only

Maternity, Paternity and Domestic

Number of documents

Total with a provision

References

Sissons L and M Law (1980) The hand that rocks the cradle... Industrial relations review. 1(6), March/April: 15-18. 